\title{
MODELOS DE PRÍNCIPES VIRTUOSOS: ABORDAGEM DOS CAPÍTULOS 19 A 27 DO LIVRO I DOS DISCORSI DE NICOLAU MAQUIAVEL RODRIGO DOS SANTOS ${ }^{1}$
}

RESUMO: O presente artigo tem por objetivo analisar e apresentar o estudo da relação dos homens com o tempo que supera de todo modo a afirmação da maldade humana e ou de uma pura e simples decadente natureza. E, apesar de aparente contradição entre a percepção da virtude ou não no príncipe, no ator político em Maquiavel, a questão posta é se - há príncipes virtuosos? Se é possível na "aparente" bondade encontrar tão somente uma substância má na perspectiva antropológica? Se considerarmos que se assim fosse, não haveria virtude e nem julgamentos dignos de elogios a serem imitados no pensamento corrente político do Florentino. Assim, sob o enfoque de três assuntos, a configuração do artigo, se analisará: (a) a teoria da virtú e da boa fortuna; (b) a necessidade do armamento, do conflito e da guerra na civiltà e (c) o modus operandis de investimento nesta formação de bons manuseadores de armas. Maquiavel, nestes capítulos do Discorsi nos dá a ideia da virtualidade dos príncipes para produção de benefícios para a república, na medida em que as sucessões e as políticas de expansão se fizerem prioridade dos seus líderes, tanto é que a verificação, pode-se ver diante da obra de Tito Lívio, quando ele citará Rômulo, que foi um rei feroz e belicoso; Numa Pompílio, rei tranquilo e religioso e Túlio Hostílio, pouco mais semelhante a Rômulo, só que mais amante da guerra do que da paz.

PALAVRAS-CHAVE: Virtú, Fortuna (boa), Armas, Milícia, Guerra.

ABSTRACT: The objetives of the folloving article to analyze and introduce the study the human beings and the the time that overcomes by any means the affirmation of the human wikedness and or, a purê and simple declining nature. And besides na apparent contradiction between the virtue perception on not based on the principle, in the political actor in Maquiavel, the asked question is abait knowing in there are virtuous princes? If possible in the "apparent" godness to find not only a bad substance in the antropologie perspective? If we consider that it was so, there wowdn't be virtue and even judgments deserving compliments to be imitated by political current thought of Florentino. Then, under the focus of three subjects, the configuration of the article, the following wil be analyzed: (a) the teory of the virtú and the good fortuna, (b) the need of weapons for the conflict and the war in the civiltà, and (c) the modus operandis of these investment in this training of good weanpon users. Maquiavel in these chapter "Do Discursi" gives us the idea of the princes virtuality to produce benefits for the republic, as long as the sucessions and expansion politics are being the priorities of the leaders to the point that the verification can be seen in the book of Tito Livio, when be talks about Rômulo, who was a

\footnotetext{
1 Professor Titular de Educação Básica II na SEE-SP. Trabalha na Escola Dr. João Pedro Cardoso, em Pindamonhangaba-SP. Mestre em Filosofia pela Pontifícia Universidade Católica de São Paulo (PUC-SP). E-mail: emaildords@yahoo.com.br.
} 
Pierce and pugnacious king, Numa Pompílio, a calm and religious king, and Túlio Hostílio a litle similar to Rômulo, but more in fawor of war than peace.

KEYWORDS: Virtú, Fortuna (good), Weapons, Militia, War.

\section{I - A reflexão sobre o modelo de "espelho de príncipes"}

Pretende-se neste artigo apresentar alguns dos textos de Nicolau Maquiavel (14681527), dispostos, sobretudo no Livro I dos Discorsi ${ }^{2}$, especificamente entre os capítulos 19 à 27, onde ele desenvolve e amplia o esteriótipo do gênero textual clássico e medievo relativo ao "espelho dos príncipes", apontando o modo de ser daquele que governa, daquele que está à frente do Principado ou da República, e que é denominado pelo conceito de "Príncipes Virtuosos". Bignotto, ao introduzir o texto de Maquiavel afirma que "os Discursos são uma manifestação das convicções republicanas de Maquiavel, uma exposição clara de suas preferências em matéria de ordenação institucional"3. É importante deixar este ponto claro, porque o Maquiavel do Príncipe não pode ser outro que dos Relatórios (que anteciparam os conceitos e a visão de mundo do Florentino, e que mais a frente comentaremos sob o título de I Primi Scritti Politici) nem mesmo no que concerne à obra analisada neste momento - Os Discorsi. Para Escorel (1984, p.24), esse "segundo momento de vida do Estado que Maquiavel se dedicou nos Discorsi", representa uma evolução especulativa em relação à doutrina formulada no Príncipe ${ }^{4}$.

O gênero que tratava da formação dos príncipes afirmava que, de um modo bem peculiar, a tradição é remota aos costumes do Egito e da Mesopotâmia e que abrange textos, de variadas formas literárias (diálogo, tratado, sermões, poemas, cartas, etc.). Sabe-se também que o gênero se desenvolveu especialmente ao longo da Idade Média, atingindo o auge entre os séculos XV e XVII. Ernst Cassirer (apud HAHN), afirma que esse tipo de literatura foi extremamente popular durante os períodos medieval e renascentista ${ }^{5}$. Na Antiguidade há obras importantes que adentram esta temática (A Nicocles, de Isócrates (436 - 338 a.C.), Ciropédia ou A Educação de Ciro, de Xenofonte (c. 430 - 355 a.C.) e a De clementia, de Sêneca (4 a.C. - 65 d.C.), mas na Idade Média, costumam-se destacar três obras mais substanciosas, tais como: o Policraticus, de João de Salisbury (1159), o De Regimine Principum, de São Tomás de

\footnotetext{
${ }^{2}$ MAQUIAVEL, (2007).

3 Ibidem, - Introdução de Newton Bignotto, p. XXVII.

${ }^{4}$ ESCOREL, (1984, p. 18-52, jul./set).

5 Cf. HAHN, F. A. "Espelhos de Príncipes: considerações sobre o gênero". História eHistória., 4.11.2008.

Disponível em: Acesso em 29.9.2020. Cf. também SENELLART, M. (2006).
} 
Aquino (1265-1266) e a obra homônima de Egídio Romano (1277-1279). Do Doutor comum, ainda pode-se destacar

De regimine principum ad regem Cypri (ou De regno), onde Tomás de Aquino (12251274) trata, entre outros, "do ofício de rei, sua aplicação e qualidades que requer a realeza de acordo com a autoridade da Sagrada Escritura, o ensino dos filósofos e o exemplo de príncipes dignos de louvor"6.

No Renascimento propriamente como eixo peculiar do artigo, destacam-se as seguintes obras: O Príncipe, de Nicolau Maquiavel (1513); Institutio principis Christiani (Educação de um príncipe cristão), de Erasmo de Roterdã (1516) e Utopia, de Thomas More (1516), sendo que este último, como observa Angelo J. Di Salvo (1989, p. 45) ${ }^{7}$, não é propriamente um guia, mas contêm muitos comentários sobre a função dos príncipes.

Ao retornarmos ao tema da virtude dos príncipes nos Discorsi, a introdução à obra exalta a capacidade de Maquiavel em - como secretário da Segunda Chancelaria, ter exitosamente trabalhado, e muito, bem como observado a dinâmica da política em movimento, mesmo que em inúmeras vezes “à meia luz”. Newton Bignotto, na introdução a obra dos Discorsi, assinala ainda que "junto aos gabinetes de administração, e responsável de realizar viagens e visitas burocráticas" o chanceler adquiriu - como já se sabe - extenso conhecimento de política e de suas articulações e adjacências. Esse modo de operar a política que ele adotou, com muita habilidade - virtú - numa das cartas enviadas a seu amigo Vettori, ele mesmo se gaba em certo sentido, dizendo: "quero que tenhas em relação aos meus problemas, o prazer de saber que os enfrentei de forma tão franca que eu próprio me aprecio por isso"8.

Assim sendo, três são os assuntos mais recorrentes na configuração destes capítulos enunciados no título: (a) a teoria da virtú e da boa fortuna como pressuposto da governabilidade eficaz; (b) a necessidade do armamento e da disposição para o conflito e para guerra e (c) o modus operandis de investimento nesta formação de bons homens manuseadores de boas armas.

Diante disso, a tese fundamental de Maquiavel está delineada no que se refere à definição de virtú do príncipe que pode manter um principado, um estado ou uma república por mais de uma geração. Atrelada a ideia de virtú, Maquiavel também apresenta a boa fortuna que corrobora às decisões prudentes de quem é o líder civil (MAQUIAVEL, 2007, p.7). Ou seja, um príncipe de virtú excelente pode fazer subsistir, mesmo depois de sua saída de cena, a sua prática política em outros príncipes sucessores que não possuem virtú suficiente e nem boa

\footnotetext{
6 SOARES (1994, p. 71).

7 DI SALVO, Angelo J. (1989, p. 43-60, Acesso em: 29.9.2020).

8 MAQUIAVEL(2007; - Introdução de Newton Bignotto, p. XIX-XX).
} 
fortuna para manter as coisas como estavam, ou seja, em ordem. Não obstante, o florentino também dispõe a ideia de que um príncipe fraco, sem virtú, não conseguirá manter-se no poder, e não terá como evidenciar as ordenações do estado se vier a ser sucedido por outro príncipe fraco. E como "só o poder dá segurança aos homens" (MAQUIAVEL, 2007, p.10) é necessário agir e pensar sobre os fatos, de tal modo que, a ideia de força se torna importante, assim como a de boas leis e boas armas, sobretudo, na execução e formação de um exército patriota.

Em defesa da dissertação de mestrado, afirmei sobre o tema

[N] nos I Primi Scritti Politici, sobretudo quando se apresenta um detalhamento "Do modo de tratar os povos rebelados do Valdichiana" (1502); (MARCHAND, 1975, p. 98-119), encontra-se expresso a intenção de nossa leitura, ou seja, verificar a teoria da força, das boas leis e das boas armas na configuração de um exército próprio para Florença. Os I Primi Scritti Politici são, basicamente, os relatórios escritos ao tempo que Maquiavel trabalhou como Segundo Secretário da República de Florença, entre 1499 e 1512. Trata-se de relatórios de participações em legazioni e commissarie $^{9}$ políticas junto aos mais destacados atores políticos da época, combinados à fina observação do desenrolar da ação encarnada pelo papa Alexandre VI e alguns de seus sucessores [no conjunto da obra maquiaveliana], o rei Francisco I, da França, o Imperador Maximiliano I, do Sacro Império e César Bórgia, que é demonstrado como modelo de príncipe pendular entre fortuna e virtù, e anterior ao último modelo, Castruccio Castracani, pleníssimo de virtù, e outros nomes e autores e atores de menor expressividade (MAQUIAVEL, 2010, p. 21) ${ }^{10}$.

Bem, nos capítulos enunciados (19 à 27) também dá-se destaque à importância das armas próprias. A virtude cívica leva o líder político a armar-se, pois, no novo cenário da ação, as armas se tornaram o instrumental mais eficiente de conquista e manutenção do poder e da liberdade. SANTOS estudando o populo afirma que "o problema militar foi uma das grandes preocupações de Maquiavel desde 1500 na cidade de Florença quando participando dos combates para a retomada de Pisa durante o governo republicano de Soderini" ${ }^{11}$ percebeu que

\footnotetext{
${ }^{9}$ Afirma Valverde que "a altura do cargo de Segundo Secretário da Chancelaria permitia somente descrever os fatos observados nas legazionni e commissarie, mesmo porque seu status social não permitia analisar e discutir política junto ao Conselho ou com a Signoria. Porém, Maquiavel a la Capitu machadiana, levanta a cabeça ao propor de maneira antitética soluções e possibilidades de movimentação do jogo político, quase sempre com uma duplicidade de alternativas pelos movimentos, sob a capa de análises e rápidas reflexões. [...] Todos os relatórios de Política e Gestão Florentina foram escritos ao longo de anos em legazioni e commissarie políticas, por regiões da Itália, da França e da Alemanha, dentre outras. Para cumpri-las Maquiavel viajava sempre a cavalo, sob os rigores ou não do inverno, atravessava, invariavelmente, a cordilheira dos Apeninos, ano após ano. Hoje, sabe-se mais de política lendo Maquiavel e acompanhando os atores políticos estudados por ele, em ação, do que perseguindo as últimas quantificações da politologia norte-americana. A experiência pode ser realizada pelo leitor atento". VALVERDE, A. J. R. "Maquiavel a cavalo: os primeiros escritos políticos", In: MAQUIAVEL, 2010, p. 25, p. 27. Cf. também: MACHIAVELLI, N. Legazioni, commissarie, scritti di governo. Tomo I. Legazione a Caterina Sforza (1498-1500). Roma: Salerno Editrice, 2002.

${ }^{10}$ Obras citadas: MARCHAND, J. J. Niccolò Machiavelli - I Primi Scritti Politici. Editora Antenore, Padova, 1975 ; MAQUIAVEL, N. Política e Gestão Florentina. Tradução e notas, Renato Ambrosio. Prefácio Kurt Mettenheim. Série Ciências Sociais na Administração, Departamento de Sociais e Jurídicos da Administração, FGV-EAESP: FSJ. Circulação Restrita. São Paulo: Multhiplic Serviços de Impressão, 2010; Cf. ainda - SANTOS, Rodrigo. Força, Armas, Leis e Milícia em I Primi Scritti Politici, de Maquiavel. Dissertação de Mestrado. Pontifícia Universidade Católica de São Paulo, São Paulo, 2015.
}

${ }^{11}$ SANTOS, L. M (2011, p.84). 
tropas externas não eram eficientes. Foi neste entrave de conflitos que Maquiavel constatou uma grande indisciplina em decorrência do uso de tropas mercenárias. Dessa indisciplina resultaram derrotas humilhantes, inclusive quando ele próprio esteve à frente de tropas militares. Em tese, pode-se acrescentar a ideia de Bignotto que acentua muito bem a necessidade do armamento em vista da preparação continente para a guerra e para o conflito, pois

\begin{abstract}
o processo de fundação e conservação de uma república não é independente da escolha de sua estratégia de defesa. A estabilidade de um regime espelha a capacidade de preparar a guerra. Sua legitimidade não decorre, portanto, somente da representatividade e constância de suas instituições, mas também do fato que ele é capaz de resolver o conflito de classes de maneira a tornar possível a conquista e a resistência (BIGNOTTO, 1991, p.156).
\end{abstract}

Fala-se ainda do investimento comedido no tocante as forças e a fortuna empregada numa situação de conflito e guerra. A recomendação não é o total investimento numa guerra sem fazer o cálculo. É preciso ter virtú acumulada para saber lidar com as situações de conflito. Tanto que, Maquiavel não se refere nos Discorsi ao príncipe robusto, mas àquele que fosse mais prudente e justo, isto entendido como o político "que enxerga longe" (MAQUIAVEL, 2007, p.15). Enfim, a guerra deve sempre ser vista tão próxima dos homens de Estado que eles devem ficar permanentemente atentos. Um bom governante, afirma Maquiavel no Príncipe, pode prever suas vitórias, deve saber os limites de sua fortuna frente a seu governo. E, sabendo que nunca um bom governante deve agir com o propósito de evitar uma guerra, pois deve saber que as guerras não podem ser evitadas, e que quando adiadas, só trazem benefícios para o inimigo ${ }^{12}$. Portanto, a virtú e a boa fortuna, as armas e o comedido investimento perfazem o modelo do "Príncipe virtuoso".

\title{
II - "Depois de um príncipe excelente pode-se manter um príncipe fraco; mas, depois de um fraco, não se pode manter reino algum com outro príncipe fraco" (Capítulo 19)
}

Uma distinção primária na apresentação do capítulo é a de que Maquiavel, em primeiro plano, afirma que o príncipe forte é aquele que possui $v i r t u^{13}$ e boa fortuna ${ }^{14}$, ou seja, é aquele que sabe fazer o cálculo político e sabe também armazená-la para momentos oportunos, pois se

\footnotetext{
12 MAQUIAVEL, (2010 - Referência ao capítulo dos "Principados Mistos" III,18). Cf. também HAHN, F. A. (2001, p. 135-138).

${ }^{13}$ Segundo Price, "há diferentes tipos de 'virtù': a moral, a política e a militar (além da combinação entre 'virtù' política e militar)" além de outras que ele trata de forma menos especificada. Cf. PRICE, R. The senses of 'Virtù' in Machiavelli, p.321-322.344. In: BENEVENUTO, (2003, p.61-62).

${ }^{14}$ Os termos: virtú e boa fortuna marcam deliberadamente a obra de Maquiavel. Para o florentino, estes conceitos subsidiam a base fundamental da conquista e manutenção do poder, bem como, da articulação e dos critérios que são essenciais naquele que estará à frente de um principado, estado e república. BENEVENUTO afirma que "no capítulo vigésimo nono do Livro II dos Discorsi, Maquiavel parece dar sequência àquilo que já havia afirmado no capítulo XXV de sua obra $O$ Príncipe: "os homens podem perfeitamente acompanhar a 'fortuna', mas não se podem opor a ela, que lhes permite urdir uma trama sem romper um só fio”. Cf. BENEVENUTO, (2003, p.70ss).
} 
não há virtú acumulada, pode a "roda" da fortuna colocar tudo a perder. Para tanto é necessário que o príncipe tenha a habilidade e o manejo político de um líder que antecipa as situações, tanto que, "assim como os homens agem por necessidade ou por escolha", os príncipes devem, em primeiro lugar, criar as boas leis $^{15}$ e estipular a ordem onde regem (MAQUIAVEL, 2007, p. 9-10)

Virtú e fortuna são conceitos fundamentais para a virtuosidade dos príncipes. E, segundo Ames (2002, p.138):

homens de virtù, para Maquiavel, são aqueles cuja vontade decidida é acompanhada de outras qualidades que possibilitam a consecução de seus objetivos: inteligência para calcular os recursos a empenhar na ação, um vivo sentido de realidade, uma rápida compreensão do que cada circunstância possibilita ou autoriza e, quando necessário, a capacidade de adotar os recursos extraordinários, de simular e dissimular, de desprender-se dos escrúpulos da moralidade corrente, sempre que isso se impõe como condição de êxito para a ação.

Sobre a fortuna, Benevenuto acrescenta:

No Livro III dos Discorsi, capítulo nono, Maquiavel faz a seguinte afirmação: “Já admiti, em vários pontos, que a causa da 'triste' ou 'boa' 'fortuna' dos homens é a conformidade da sua conduta com os tempos em que vivem. Pode-se observar, de fato, que a maior parte dos homens age ou com precipitação ou com excessiva lentidão. Nos dois casos se comete um equívoco, afastando-se do caminho apropriado e dos limites adequados. Por outro lado, quem só age de acordo com o seu tempo está menos sujeito a erro, e fica mais próximo da 'fortuna"' ${ }^{\prime \prime}$.

Num segundo plano do capítulo 19, Maquiavel define a oposição do príncipe virtuoso, ou seja, o príncipe fraco. Este é aquele que, não possuindo as mesmas qualidades de seus antepassados, não pode manter por si só no reinado, à frente de um estado. Disso decorre, nas entrelinhas do texto que o "tempo de guerra" e a aptidão para ela, bem como a prudência e a virtú são mais eficientes do que o "tempos de paz"17. Em outras palavras, o bom governo e o bom governante são mais excelentes e bem alinhados quando são postos à prova, no que se

\footnotetext{
${ }^{15}$ As boas leis indicam a contenção dos homens. Norberto Bobbio afirma na obra "O terceiro ausente" (p. 148) que a "função primária da lei é conter, e não liberar, restringir e não ampliar os espaços de liberdade, endireitar a árvore torta e não deixar que ela cresça de modo selvagem". A partir do momento em que se institui as boas leis, afirma Maquiavel, o príncipe evita que os homens, ao procurarem satisfazer seus desejos individuais, prejudiquem a ordem interna do principado [trata-se da questão dos humores], (MAQUIAVEL, Livro I, capítulo 3, p. 20). Não há política sem leis, tanto que, complementa Maquiavel: “[...] a fome e a pobreza tornam os homens industriosos, mas as leis os tornam bons" (MAQUIAVEL, 2007, p.20).

${ }^{16}$ BENEVENUTO, (2003, pp.78).

${ }^{17}$ Os ditos, longos períodos de ozio (paz) são descritos por Maquiavel. A paz e a liberdade devem ser compreendidas como resultados concretos e dinâmicos da convivência em comum. Conforme explica Negri, "[...] o equilíbrio das forças não é uma forma que o poder impõe ao conflito social, mas o resultado dos conflitos sociais. A trégua não passa de um momento na fisiologia constitucional. Em contrapartida, a expressão contínua das potências constituintes é orgânica. A anarquia e a guerra civil só podem ser exorcizadas deste modo, e somente com esta imagem a democracia será um antídoto". Cf. NEGRI, (2002, p.271).
} 
denomina "tempo de guerra" ou necessidade do conflito ${ }^{18}$. Quem não está acostumado à guerra tende a ser mais frágil nas relações de poder, portanto, mais suscetíveis à derrota em combates e submetidos a perda da liberdade.

Maquiavel tinha como subtexto destes capítulos a obra romana de Tito Lívio, sobre a História de Roma, principalmente o Livro I, dos capítulos 4 à 32, onde encontra-se as seguintes ideias mais importantes para análise do florentino.

Tito Lívio narra a "Lenda do nascimento de Rômulo e de Remo", destacando a ação de Larência, a prostituta, a "loba", que cuidou dos pastorzinhos até pouco antes de sua juventude (TITO LIVIO, 1989, p.25-26). Destaca-se ainda na narrativa o "Assassinato de Amúlio", a "Fundação de Roma" e a "Morte de Remo" (p.26-30). Adjunto ao tema da virtuosidade do governante, Maquiavel lê a questão da "Organização de Roma na escolha dos Senadores" e de tal leitura, destaca-se a postura que Tito Lívio dá à questão da honra (descendência patrícia) como marco da escolha dos homens condutores do povo (p.30-31). Pode-se ler aqui, de algum modo, a tendência e o humor dos grandes. Há uma sequência interessante onde Tito Lívio demonstra como o estado romano estava preparado para enfrentar com armas iguais seus estados vizinhos (p.31). Nesta sequência da obra destaca-se (p.31-37): “O Rapto das sabinas”; "A guerra contra os ceninenses, com vitória dos romanos"; "A traição e a morte de Tarpéia"; "O combate contra os sabinos", sobretudo no detalhe narrativo de que o comandante organizava suas tropas como quem possuía "uma voz divina” (TITO LÍVIO, 1989, p.37). Sabe-se que a religião romana é estudada por Maquiavel nos Discorsi (Cf. 2007, p.44-64), e que, segundo o Prof. Dr. Valverde, "ela é cimento de coesão social". Bem, ocorre ainda na obra de Tito Lívio a questão da "Aliança entre Rômulo e Tácio", "A vitória sobre os fidanetes", onde estes, enquanto ditos "uma potência" foram devastados, levados ao apavoramento pelos romanos (p.40). Conta Tito Lívio que os veienses, por terem o mesmo sangue dos fidanetes vieram para combate, mas foram dizimados também. Eles chegaram a enviar uma delegação para Roma para pedir paz, o que aconteceu por mais de cem anos (p.40). Tito Lívio narra ainda: “A morte

\footnotetext{
18 Sobre a importância e a inevitabilidade do conflito, afirma AMES: "o conflito não está limitado à oposição interna à questão dos "humores" de grandes e povo. Este é o ponto, talvez, mais visível, mas seria um equívoco reduzir tudo a esse confronto. Com efeito, além da oposição dos "partidos" no interior do Estado, o conflito das paixões está igualmente na base da rivalidade entre os indivíduos singulares, assim como da guerra entre os Estados. Assim sendo, é preciso ter presentes alguns pontos importantes. Por um lado, o conflito permanece irresolvido, o que significa dizer que, em vez de a política ser a neutralização dele, o máximo que ela consegue é ser sua regulação. Por outro lado, uma vez que o conflito não se esgota intramuros, mas se manifesta também na expansão dos Estados, há uma ligação íntima entre política e guerra. Por fim, do conflito (em quaisquer de suas três formas - como rivalidade de paixões entre singulares; como oposição dos humores de partidos e como guerra) não é possível determinar a priori sua natureza - construtiva ou destrutiva -, mas apenas a partir das circunstâncias concretas nas quais se manifesta”. Cf. AMES, (2011, p.23).
} 
de Rômulo"; a luta pelo trono, pelo poder que sucedeu a morte de seu líder, "A Sagração de Numa Pompílio", muito citado por Maquiavel, "As primeiras reformas de Numa"; "A criação dos colégios sacerdotais"; “A consagração às Camenas e a Festa de Boa fé”, onde ocorre o fim da liderança de Numa (TITO LÍVIO, 1989, p.41-49). Seguidamente vem a "Sucessão de Tulo Hostílio", "A advertência que Tulo faz à Métio Fufêncio", bem como o "Tratado entre os romanos e os albanos" (p.50-53). No Livro I dos Discorsi, Maquiavel dá ênfase ao capítulo 25 da História de Roma, onde se encontra o "Combate entre os Horácios e os Curiácios". Subsequentemente o texto de Tito Lívio narra: "O crime e o castigo de Horácio", "A traição e a execução de Métio"; "A destruição de Alba" e a "Guerra contra os sabinos" (TITO LÍVIO, 1989, p.54-61). Quase no fim deste subtexto, presente no capítulo 19 dos Discorsi, e que fundamenta e justifica que um príncipe fraco não pode suceder outro príncipe fraco, mas que um príncipe de virtú pode fazer valer as estratégias de sua postura de governo em outros tempos, mesmo que o líder do cenário não tenha virtú suficiente e não conte com a boa fortuna, Tito Lívio narra: "A morte de Tulo Hostílio"; "A eleição de Anco Márcio, bem como a declaração de guerra contra os latinos e a vitória conquistada". Encerra-se o subtexto com a "Chegada dos Tarquinios a Roma" (TITO LÍVIO, 1989, p.62-69) ${ }^{19}$.

Esta leitura da obra de Tito Lívio fundamenta e enfatiza que um príncipe fraco pode suceder um príncipe forte, mas um príncipe fraco não pode suceder outro príncipe fraco. Príncipes fortes não deixam o reinado parar. Ao contrário, para Maquiavel, o reinado e/ou principado parados é sinal de fraqueza. A paz é uma busca, porém, é a guerra que provoca a fortaleza do príncipe. Portanto, "príncipe fraco são os que não se ocupam da guerra" (MAQUIAVEL, 2007, p.78).

Deste modo, Maquiavel, no cap. 19 do Livro I dos Discorsi analisa a virtú e a imensa fortuna de alguns príncipes romanos que souberam ler "os sinais dos tempos" e "calcular a dinâmica de procedimento na vida política". A proposição defendida por Maquiavel é a de que a virtú é essencial para o bom êxito do governo, isto previsto enquanto conquista e manutenção do poder. Maquiavel mesmo descreve em relação aos reis e príncipes: "[eles] souberam proceder" (MAQUIAVEL, 2007, p. 76), e por isso são, modelos de fortaleza e um referencial da nova ótica das ordenanças. Maquiavel ainda parte do princípio de que a virtú de um "bom príncipe" garante e mantém o estado para o próximo príncipe. E, mesmo se o sucessor não tiver tanta virtú, ou esta não for suficiente para a ocasião ${ }^{20}$, a virtú e a obra deixada pelo antecessor

\footnotetext{
${ }^{19}$ Cf. LIVIO, Tito, (1989, p. 25-69).

${ }^{20}$ Por ocasião, Maquiavel entende que o príncipe deve agir. Para o florentino, não há uma conduta a priori boa ou a priori má. Ao encarar a política como uma técnica, o julgamento das ações do governante só pode se dar a
} 
faz ainda os frutos se revigorarem (MAQUIAVEL, 2007, p.77). Sem virtú suficiente no governo posterior, o reino se arruína.

Maquiavel diante da obra de Tito Lívio a pouco apresentada, cita Rômulo, que foi um rei feroz e belicoso; Numa Pompílio, rei tranquilo e religioso e Túlio Hostílio, pouco mais semelhante a Rômulo, só que mais amante da guerra do que da paz (MAQUIAVEL, 2007, p.77). Nos primórdios de Roma, para se efetuar a ordenação da vida civil, foi necessário um rei como Rômulo. E de tempos em tempos, o modo de Rômulo, a ferocidade e a belicosidade deveriam ressurgir para não tornar Roma uma cidade frágil, efeminada ${ }^{21}$ e presa fácil (MAQUIAVEL, 2007, p.77). Elogia Rômulo como um governante de "grande virtú" (MAQUIAVEL, 2007, p.78)22. Quem se assemelha, por exemplo, a Numa pode manter ou não o estado, é indeterminado, é fortuna, porém, aquele que se assemelha a Rômulo manterá o estado de qualquer modo, pois está investido de "prudência e de armas", e pode ser surpreendido somente com algum tipo de "força extraordinária"23 (MAQUIAVEL, 2007, p.78). Maquiavel descreve Davi ${ }^{24}$, Rei de Israel, como alguém de "tanta virtú", de tal modo que, por ser excelente

posteriori, em função de sua eficácia na prática, naquilo que se designa ocazione, ou seja, a conduta de conquistar o poder, conservar o poder ou promover o bem coletivo deve ser um fato de atenção permanente para quem governa. Assim sendo, não existem fins que justifiquem meios. Existem fins que devem ser perseguidos. A leitura de mundo, a percepção da ocasião é o sinal virtú para ser o príncipe virtuoso. Nos Discorsi o tema da ocasião aparece no Livro I, capítulos 9 [De como é preciso estar só para se ordenar uma república nova ou para reformála inteiramente com ordenações diferentes das antigas] e 42 [Da facilidade de se corromperem os homens], (MAQUIAVEL, 2007, p. 40-43; 131).

${ }^{21}$ A imagem da mulher para Maquiavel. "O mundo das obras políticas de Maquiavel, onde os homens competem na arena da história, e, na verdade, dominado, ou pelo menos continuamente ameaçado nos bastidores, por figuras femininas de imenso poder, mal percebidas e espectrais. Em aspectos cruciais, a competição entre os homens acaba por ser sua luta comum contra esse poder. O feminino constitui "o outro" de Maquiavel, em oposição a masculinidade e a autonomia em todos os sentidos: as condições de homem, de adulto, de humano, bem como a política. [...] Como contrapartida ao seu conceito de virtù, nenhum epíteto e mais frequente ou mais poderoso no vocabulário de insultos de Maquiavel do que "afeminado". [...] No entanto, ao mesmo tempo em que são desprezíveis, tolas e fracas, de alguma forma as mulheres também possuem poderes misteriosos e perigosos; constituem uma ameaça aos homens, tanto no plano pessoal quanto no político. [...] Pode-se ler até mesmo "Como se arruína um estado por causa de mulher", como se anuncia nos Discorsi (MAQUIAVEL, Livro III, capítulo 26, 2007, p. 401). Em suma, [...] o poder da feminilidade e um tema complexo para Maquiavel, centralmente entrelaçado com preocupações políticas. As mulheres jovens são perigosas como objetos desejáveis, ameaçando debilitar os homens e os privatizar. As mulheres mais velhas, uxoriais e matronais, tem personalidade e capacidade de agencia, mas os seus propósitos provavelmente serão malévolos, principalmente quando estiverem com raiva, o que acontece com frequência. Seus poderes, portanto, aproximam-se do sobre-humano e fazem encolher os dos homens". Cf. PITKIN, (2013, p. 219-252).

${ }^{22}$ Maquiavel cita ainda os rômanos: Tulo e Anco.

${ }^{23} \mathrm{O}$ termo extraordinário para Maquiavel tem relevância porque designa o que se opõe à finalidade normal da política, bem como a gravidade extrema da situcionalidade. Refere-se ainda ao recurso e aos meios que fogem ao que é comum (aos "modos ordinários". Tais meios devem ser compreendidos como os que são da ordem da violência, e que costumam ser proscritos pela política porque sua finalidade é fazer o Estado durar (MAQUIAVEL, 2007, Livro I, 34, p.106-109 e. Cf. MÉNISSIER, (2012, p.22).

${ }^{24}$ Com a ascensão de Davi ao trono de Israel, "o exército popular dos homens livres de Israel tornou-se uma tropa auxiliar do exército de mercenários. Nessa função subordinada, eles deviam obediência militar a Davi, também nas guerras de agressão contra os povos vizinhos". Tal função desfigurava o caráter original desse exército, porém, por outro lado, fornecia ao rei Davi uma tropa auxiliar muito útil para as suas conquistas e busca de poder. A guerra para Davi tornou-se um instrumento político de poder na mão do rei e, por isso, "a partir de Davi já não se 
nas armas, pode dar ao seu filho e sucessor Salomão ${ }^{25}$, também "grande rei", pela tradição de Israel, uma importante situação de pacificação em Israel. Nestas condições Salomão pode governar com a arte da paz, e não com guerra, gozando dos frutos da virtú de seu pai (MAQUIAVEL, 2007, p.77). Não obteve o mesmo sucesso Roboão ${ }^{26}$, filho de Salomão e neto de Davi. Ele não herdou nem a virtú do avô, nem a boa fortuna do pai. "Viveu a duras penas com a sexta parte do reino" (MAQUIAVEL, 2007, p.77). Maquiavel também exemplifica com Baisit, sultão dos turcos, gozou dos frutos do trabalho de seu pai, Maomé27. E diz que Salim, "atual senhor", se assemelhou ao avô, e não ao pai, o que levaria o reino às ruínas. Salim está preste a superar até mesmo a glória do avô (MAQUIAVEL, 2007, p.78). Assim se justifica o primeiro tema a ser tratado, a questão da teoria da virtú e da boa fortuna como pressupostos da governabilidade eficaz.

\section{III - "A sucessão de dois príncipes virtuosos produz grandes efeitos; e como as repúblicas bem ordenadas têm necessariamente sucessões virtuosas, sendo, portanto, grandes as suas conquistas e a sua expansão" (Capítulo 20)}

pode mais legitimar a figura do rei como o libertador enviado por Deus". Davi, além de governar o povo, exercia a função de juiz (II Sm 8,15). O governo de Davi sempre enfrentou certa oposição dos anciãos pertencentes ao antigo regime tribal de Israel. Foram esses anciãos que apoiaram Absalão em sua revolta contra Davi (II Sm 15,1012). "A política de Davi para com as cidades litorâneas fenícias, a respeito da qual não temos nenhuma informação, deve ter sido de prudente discrição, semelhante à atitude geralmente adotada mais tarde pelos soberanos do império neo-assírio". Cf. ALBERTZ, Rainer (1999); CAZELLES. Henri (1987) e DONNER, Herbert, (1997).

${ }^{25}$ Salomão, assim como o seu pai Davi, era o responsável pela execução da justiça em Israel, pois, em Israel a justiça se liga ao coração da Torah, ou seja, remonta à justiça mosaica, a qual o rei deveria exercitar-se para resolver casos difíceis (I Rs 3,16-18) que nem os escribas conseguiam. Salomão, para bem poder governar, eliminou aqueles que se opuseram à sua eleição real. Mandou Benaiá matar o príncipe Adonias, quando este reivindicou para si a concubina de seu pai Abishag, a shunamita, (I Rs 2,13-25), por ver neste gesto de Adonias ainda uma intenção de tomar-lhe o trono. No que se refere à política externa, Salomão dominou todos os reinos a partir do Eufrates até a fronteira com o Egito (I Rs 5,1). Salomão também continuou a dominar a região dos filisteus que lhe pagavam tributos e lhe serviam. (I Rs 5,1). Salomão dominou ainda a região Transeufratênia desde Tifsah até Gaza (I Rs 5,4). Salomão durante o seu reinado viveu em paz com os povos das suas regiões limítrofes (I Sm 5,4). Para manter esta paz ele fazia alianças com os povos por meio de casamentos. Assim, de acordo com a tradição bíblica, Salomão montou um harém com mil mulheres das quais setecentas eram de estirpe principesca (I Rs 11,3), entre as quais a filha do Faraó (I Rs 11,1). Essa quantidade de mulheres estrangeiras é apontada pelos hagiógrafos como a causa da ruína de Salomão que teve seu coração desviado do Senhor por essas mulheres (I Rs 11, 3-5). Cf. BRIGHT, John. (2003); CAZELLES. Henri, (1987).

${ }^{26}$ Enquanto Roboão, filho de Salomão e neto de Davi, era rei de Judá, o povo de Judá pecou contra Deus e deu mais motivos para que Deus ficasse "irado" [antropomorfismo] do que todos exemplos e fatos que os antepassados haviam dados. Eles construíram altares nos morros para adoração de falsos deuses e, no alto dos morros e debaixo das árvores que dão sombra, levantaram colunas de pedras e postes-ídolos para adorar. No quinto ano do reinado de Roboão, Sisaque, rei do Egito, atacou Jerusalém. Sisaque levou embora todos os tesouros do templo e do palácio e também os escudos de ouro que Salomão havia feito. Roboão, segundo Maquiavel, era príncipe fraco, nem tendo e nem usufruindo das "virtús" de seu pai e avô. Cf. BRIGHT, John, (2003).

${ }^{27}$ Segundo a crença islâmica, Maomé recebeu a primeira revelação em 610 d.C, através do arcanjo Gabriel. Inicialmente pregou apenas entre seus familiares e amigos. Aos poucos tentou converter também os moradores de sua cidade, Meca, um centro de peregrinação de diversas tribos árabes. Sua insistência no monoteísmo foi vista como uma ameaça ao comércio da cidade, que vivia dos peregrinos de diversas religiões. Maomé é tido como homem de virtú porque utilizou-se da religião como ponto de convergência e unidade, de poder entre os seguidores, não só do culto, mas da ideologia política, como se vê até em nossos tempos. 
Maquiavel, neste capítulo 20, quer estabelecer a seguinte ideia: propõe que uma república que deve ter em seu ordenamento "infinitos príncipes virtuosíssimos", ou seja, homens que sejam de comprovada capacidade de cálculo e de leitura dos tempos frente às ocasiões. Como já disposto no capítulo anterior, a virtú é o mensurador da capacidade de conquista e manutenção do poder e da liberdade de um príncipe. E isto se faz de tal modo que, assim como ocorreu entre Felipe da Macedônia e Alexandre, o Grande, como conquistadores do mundo. Pode também ocorrer com Roma, de acordo com a eleição, sucessão e ordenação dos líderes. Depois da expulsão dos reis fracos e maus, daqueles que expunham Roma ao perigo, que não tinham condições de governo forte, e não imitavam seus antecessores próximos ou um pouco mais distantes, o estado deve se "armar" personificadamente, militarmente e economicamente. Os Cônsules que tomaram o poder, não pela via da herança, da fraude ou da ambição violenta, mas por sufrágio livre, eram homens excelentes, de comprovada virtú e de boa fortuna (MAQUIAVEL, 2007, p.79). Assim sendo, a virtú produz efeitos benéficos para o principado ou república, na medida em que as sucessões e as políticas de expansão se fizerem prioridade dos seus líderes.

\title{
IV - "Da censura merecida pelo príncipe e pela república que não tem armas próprias" (Capítulo 21)
}

Maquiavel ao tratar da importância das armas próprias, cita um trecho da Eneida de Virgílio, marcando a virtú de Tulo entre os romanos: “[...] e Tulo levará os homens ociosos ás armas". Especificamente assim se lê

\begin{abstract}
mas a quem vejo, cingida a cabeça com um ramo de oliva, sacras oferendas nas mãos? Pelas cãs o conheço e essas barbas: é o rei de Roma, sim, Numa, o primeiro a dar leis a sua gente, e que, Cures modesta partindo, há de alçar-se ao domínio de um vasto império, seguido ali mesmo de Tulo potente, que porá termo esta fase de paz para armar guerreiros, desabituados em tanta inação às belezas do triunfo (VIRGILIO, Eneida, Livro VI, 810-815) ${ }^{28}$
\end{abstract}

\footnotetext{
${ }^{28}$ VIRGILIO, Eneida. (2014). O livro VI é o centro da obra de Virgílio, pois narra a descida de Eneias ao mundo dos mortos/infernos [catabase], e que de certa forma, encerra metade da odisseica, errância no mar, para dar início a metade iliádica, a luta em terra. Esta "descida" evoca elementos da filosofia platônica e da doutrina órfica, sobretudo no trato da temática da metempsicose. Há no mundo antigo um interesse para com os personagens infernais e poética dos jogos temporais. Nos vv.1-97, a sacerdotisa Sibila introduz o herói Eneias ao templo e a manifestação de deus. Eneias quer ir à presença de seu pai. Ele sabe da morte de Miseno, encontra o ramo de ouro e duas pombas brancas, e prestando culto aos deuses infernais, continua sua saga (vv.97-263). Encontra-se com várias divindades, dentre as quais destacamos: o Medo, a Velhice, a Fome, a Morte, as Guerras, a Discórdia, etc. (vv.264-295). Guiado sempre por Sibila encontra-se com Cérbero, o cão de guarda. Passa por onde se contra as almas de crianças, suicidas e de quem morreu por amor, chamado de Campos Lugentes, onde está Dido (vv.450476). Encontra também os guerreiros de Tróia que forma mutilados pelos gregos (vv.477-539). Sibila continua a levar Eneias pelas moradas de Plutão e Campos Elíseos, no encontro com suplícios de adúlteros, incestuosos, parricidas e sediciosos (vv.54-627). Depois vão ao palácio de Plutão e Prosérpina (vv.628-686). Eneias, enfim, junto ao rio Letes, encontra seu pai (vv.687-751). Eneias pôde contemplar as reencarnações, tais como a do rei Rômulo, Pompeu, César e até mesmo do infeliz Marcelo (vv.752-885). Por fim, entre os sonhos falos e verdadeiros, Eneias sai e encontra seus companheiros (vv.886-901), (2014, p. 369-371).
} 
Poucos antes do Príncipe, ainda como Segundo Secretário de Florença, nos relatórios que produziu entre os anos 1498-1512, Maquiavel assevera sobre a importância e a necessidade do amparo militar - pois política se faz com força armada [Discurso Proferido ao Magistrado dos Dez Sobre a Situação de Pisa]. A força é a garantia da unidade política. Trata-se da conservação de um estado diante das contínuas ameaças e dos constantes confrontos a que estava sujeita a Itália. Neste caso, os pactos não são suficientes, pois eles somente são garantidos pela força. A regra de que lança mão para concluir o argumento lembra-nos Hobbes descrevendo a situação de guerra: "porque toda cidade, todo estado, deve considerar inimigos todos aqueles que pensem ser possível ocupar o seu [estado] e de quem vocês não se podem defender" 29 . Assim, a respeitabilidade e subsistência de um estado somente são obtidas com a força e esta depende, na ordem das razões do florentino, da possessão de exércitos e armas próprias, pois como afirma SKINNER a: "ausência das armas representa um dos fatores determinantes para o fracasso político".

Então, por onde começar a se armar? A resposta de Maquiavel, provém desde os relatórios dos Primeiros Escritos de Política - o projeto deve começar pelo recrutamento no campo. Primeiramente, a escolha do campo não é aleatória, é algo premeditado nos Escritos políticos. É preferível a realidade campineira. Isto porque escolher a cidade para o recrutamento do exército já é, ainda que de maneira genérica, compô-lo por homens que comandam e homens que obedecem, por homens que combatem a pé e homens que militam a cavalo e, tendo de introduzir o exército em uma província desacostumada às armas, é necessário, como em todas as outras disciplinas, começar pela parte mais fácil, no caso, o campo e os homens que ali residem (MAQUIAVEL, 2010a, p.55) ${ }^{30}$. Maquiavel também - ainda para defender a ideia do início no campo, afirma que

$$
\begin{aligned}
& \text { não seja aconselhável começar pelo distrito, mesmo que nele se possa introduzir a } \\
& \text { milícia a pé, porque não seria uma medida segura para a vossa cidade, principalmente } \\
& \text { naqueles lugares do distrito nos quais há cidades ou aldeias com fortalezas e nas quais } \\
& \text { também uma província possa resistir" (MAQUIAVEL, 2010, p. 56). }
\end{aligned}
$$

No Príncipe, capítulo XII ${ }^{31}$, que trata de "Quantos são os gêneros de milícias e das milícias mercenárias", Maquiavel descreve que os bons fundamentos, tal qual as boas leis e as boas armas, que o príncipe deve ter e manter, para que não se arruíne a si próprio e ao seu estado (XIII, 2-3) está na sua prudência de provir "armas e exército próprios" (XII, 11-12). As armas

\footnotetext{
${ }^{29}$ MACHIAVELLI, N. "Parola da dirle sopra la provisione del danaio facto un poco di proemio et di scusa", 1997, p. 13, In: PANCERA, (2010, p. 105).

${ }^{30}$ MAQUIAVEL, N. (2010, p.55-56).

${ }^{31}$ Ibidem, (2010b, p. 131-141).
} 
apresentadas no capítulo são variadas. São elas: as próprias, as mercenárias e as auxiliares ou mistas. De todas elas o aceno mais virtuoso está nas armas próprias (XII,4). A Itália por longos anos ficou a mercê das armas mercenárias, até mesmo quando os padres estiveram no comando, deram aos forasteiros encargo de proteção, e isso foi devastador. Nas mãos de homens sem virtú suficiente a Itália foi "devastada por Carlos, saqueada por Luís, subjugada por Fernando e vituperada pelos suíços" (Cf. XII, 24-31). As armas mercenárias e auxiliares são inúteis, e em última instância não dão segurança ao Estado. Tais armamentos são fundados, tão somente, no "soldo", no dinheiro (XII, 5-7), que nos Discorsi pode se ler: "o dinheiro não é o nervo da guerra" (MAQUIAVEL, Livro II, 10, 2007, p. 213). E Maquiavel faz ainda um comentário - "é por isso que a Itália está em ruína" (XII, 8-9), por confiar em tropas mercenárias. Maquiavel fala também do capitão mercenário, que tendo ou não virtú pode se arruinar e arruinar aos que o contrataram (XII, 10). Fica claro até aqui que a primeira coisa que um "príncipe virtuoso" deve pensar é a guerra. Nos Discorsi, ao pensar e refletir sobre a religião romana, Maquiavel afirma que depois dos "fundadores de religião", os comandantes de exército têm seu mérito nas articulações do estado. Eles também devem possuir virtú para comandar o exército e o povo, ao ponto que o próprio Maquiavel prefere teoricamente um grupo de soldados mais enfraquecidos do que um comandante sem virtú, um comandante fraco (MAQUIAVEL, 2007, p. 44. Livro III, 13). Relendo a histórias das repúblicas e dos homens armados, Maquiavel chama a atenção para o empreendimento da guerra com armas próprias, tendo nos gentis homens e na plebe armada, de maneira muito virtuosa, a sagacidade com que estes dispuseram ações políticas na Itália Renascentista (XII, 13-23) ${ }^{32}$.

Para tanto, a falha crucial e capital de um rei e príncipe é não estar preparado para guerra. O tempo de paz não propicia a fortaleza de um reino. Um reino forte é aquele que está, mesmo no tempo da paz, preparado para as ordenações da guerra (MAQUIAVEL, 2007, p.80). Maquiavel começa este capítulo afirmando que "'é uma vergonha, príncipes atuais e repúblicas modernas que não tenham soldados próprios" (MAQUIAVEL, 2007, p.79), pois onde há homens deve haver soldados. E ainda exemplifica, que em 1513, o rei da Inglaterra atacou o reino da França, e o fez com soldados de sua pátria. A França estava desacostumada à guerra, afirma Maquiavel, isso porque há mais de trinta anos não tinha soldados e nem comandantes que já tivessem combatido (MAQUIAVEL, 2007, p. 80). Enfim, é preciso estar acostumado as armas.

${ }^{32}$ MAQUIAVEL, (2010b, p. 131-141). 
Tulo encontrou Roma em tempo de paz, não obstante, não achava entre os concidadãos homens acostumados a guerra, porque no tempo de Numa não houve guerra em Roma. Tulo, que era homem prudentíssimo, não quis embargar em soldados mistos ou mercenários, tais como os samnitas e os toscanos, mas deliberou sobre os seus homens mesmo (MAQUIAVEL, 2007, p.80). Superando a fraqueza de Numa, Tulo, de grande virtú, em pouquíssimo tempo, conseguiu fazer "soldados excelentes" (MAQUIAVEL, 2007, p.80). Pelópidas e Epaminondas libertaram Tebas, primeiro porque tanta eram suas capacidades, a sua "virtú", e depois, mesmo em meio a povos efeminados (fracos), não hesitá-los em arregimentá-los em exércitos para combate. Em suma, o conflito e a formação patriota, própria do estado prepara a fortaleza interna e externa de um principado ou república.

\section{V - "Daquilo que se deve notar sobre os três Horácios, de Roma, e os três Curiácios, de} Alba" (Capítulo 22)

Segundo Maquiavel, que lê a obra "História de Roma" de Tito Lívio, afirma que Tulo, rei de Roma, tinha mais virtú do que o rei Mécio de Alba, ao ponto que, no confronto dos três Curiácios, de Alba, com os três Horácios de Roma, os primeiros foram derrotados. Mécio e os albanos ficaram sujeitos aos romanos. Horácio ao voltar para casa matou também sua irmã que chorava a morte de um dos Curiácios, seu marido. Este Horácio foi julgado e libertado por este erro, de matar sua irmã, graças aos rogos de seu pai (MAQUIAVEL, 2007, p.81-82). Três situações notáveis destaca Maquiavel: primeiramente "é que nunca se deve arriscar toda a fortuna como parte das forças, uma segunda, as culpas nunca são compensadas pelos méritos, como demonstrou no caso do Horácio que matou a irmã, e por fim, nunca são sábias as decisões, quando se deve ou se pode desconfiar de sua inobservância (MAQUIAVEL, 2007, p.82). Deste cenário de confronto, Mécio e seu povo ficam submissos ao povo romano. A servidão não é uma situação fácil, porém, Mécio tentou enganar Tulo através de uma obediência enganosa, mas sem tomar a devida percepção que deve se fazer nestes eventos, do que se denomina temeridade (MAQUIAVEL, 2007, p. 82). O capítulo, portanto, envolve o comedido investimento na guerra, bem como questões de meritocracia e heteronomia das leis e relações sociais.

VI - "Que não se deve pôr em risco toda a fortuna nem todas as forças, e por que muitas vezes é danosa a defesa de desfiladeiros" (Capítulo 23)

Maquiavel neste capítulo faz uma dupla constatação: em primeiro lugar, crítica a Tulo, mesmo que este tenha saído vencedor do confronto contra os Albaneses, e a Mécio, o próprio rei de Alba. Em segundo lugar, refere-se a pouquíssimos comandantes que escolhem lugares mais adequados para o confronto e para o embate. Diz o florentino que "são raros os 
comandantes que guardam os desfiladeiros" (MAQUIAVEL, 2007, p. 84). Maquiavel parte de um pressuposto que nunca foi contrariado, ou seja, a decisão de pôr em risco toda fortuna e todas as forças numa situação que envolva a história e o bem de todos numa república. Tulo e Mécio confiaram toda a fortuna e virtú da pátria à três homens como representantes e com isso tornaram vão todo o trabalho de seus antecessores. Mesmo os Horácios romanos que saíram vencedores, como há pouco se relatou, não conseguem em si mesmos darem conta de toda a virtú que possa existir em Roma. Muito menos os Curiácios, que no micro cenário da disputa perderam, não tiveram virtú suficiente (MAQUIAVEL, 2007, p.82-83). A crítica de Maquiavel se estende a ideia de que é errôneo e danoso o investimento de não guardar os desfiladeiros como ponto estratégico de combate, ou em locais onde se prevê maior dificuldade de manter as forças ordenadas a acomodadas. É danoso, insiste Maquiavel, esperar o inimigo (potente) em local "acolhedor e não montanhoso", pois o inimigo está em avanço e ataca em momento oportuno, enquanto o exército que está em espera, precisa além da observância do combate, tomar cuidado com outras situações, tais como o zelo pelo acampamento. $\mathrm{O}$ fato de escolher locais não adequados para a batalha acarreta um desfavorecimento, não só relativo ao quantificador, mas também às condições efetivas de embate, como o terror de ser posto à prova e o arriscar a boa fortuna (MAQUIAVEL, 2007, p.83-84). Citando novamente a obra de Tito Lívio $^{33}$, Maquiavel narra as dificuldades de Aníbal no que se refere ao transpor as montanhas entre a Lombardia, a França e a Toscana, bem como a vitória dos romanos antes de Ticino, depois da planície de Arezzo. Aníbal foi esperado e seu exército dizimado pelos romanos num lugar que havia a possibilidade de vitória, e não antes, já destruído pela, segundo Maquiavel, "aspereza do lugar" (MAQUIAVEL, 2007, p.84). Maquiavel cita um último exemplo ao narrar que, em 1515, o rei Francisco da França, que pretendia adentrar à Itália, venceu os suíços, porque se utilizou de um caminho desconhecido, de tal forma que os surpreendeu, deixando-os apavorados em Milão (MAQUIAVEL, 2007, p.85). O capítulo aponta, portanto, além da preparação efetiva do exército, da virtú militar, das condições do comandante, a questão geográfica, o melhor lugar, "menos áspero" para se enfrentar com maior incidência para vitória os inimigos.

VII - "As repúblicas bem-ordenadas instituem prêmios e penas para seus cidadãos, e nunca compensam estas com aqueles"34 (Capítulo 24)

As repúblicas bem-ordenadas instituem prêmios e penas para seus cidadãos, e nunca

\footnotetext{
${ }^{33}$ TITO LIVIO, (XXI, 32-37 e 58; 1989).

${ }^{34}$ Ibidem, (XXI, 32-37 e 58; 1989, I, 22-30). Cf. MAQUIAVEL, (2007, p. 85-87).
} 
compensam estas com aqueles. Horácio vencera os Curiáceos com virtù, foi aclamado e tido como herói, porém matou a irmã e foi levado a julgamento. "Nenhuma república bem -ordenada jamais usou méritos de seus cidadãos para anular deméritos". Estas ordenações quando bem observadas garantirão a civiltà, sem prejuízo da república. É importante aplicar as penas pelas más ações, e premiar aqueles por seus méritos. Mesmo que a república seja pobre é importante honrar com prêmios seus cidadãos destacados.

VIII - "Quem quiser reformar um estado antigo, transformando-o em cidade livre, deverá manter pelo menos algum vestígio dos antigos modos"35 (Capítulo 25)

Quem quiser reformar um estado antigo, transformando-o em cidade livre, deverá manter pelo menos algum vestígio dos antigos modos. Aquele que quiser reformar o estado de uma cidade, deverá manter antigos modos, pois o povo se sensibiliza mais pelo que parece, do que pelo que efetivamente é. Preservar nomes de cargos e símbolos, preserva o antigo, e mesmo que o conteúdo seja totalmente diferente, haverá respeito e equilíbrio no novo governo.

IX - Cap. 26 - Um príncipe novo, em cidade ou província por ele tomada, deve renovar tudo $^{36}$

Um príncipe novo, em cidade ou província por ele tomada, deve renovar tudo. Aquele que tiver bases fracas deverá construir novo governo com nova denominação. Criar novas cidades, demolir as já existentes, transferir habitantes sem deixar nada intacto da antiga província. Fazer com que toda nova ordem, cargo ou riqueza sejam atribuídos a causalidade do novo príncipe. Como exemplo histórico temos Filipe da Macedônia, que projetou-se de pequeno rei para ser o grande príncipe da Grécia.

\section{X - Cap. 27 - Raríssimas vezes os homens sabem ser de todo maus ou de todo bons ${ }^{37}$}

Raríssimas vezes os homens sabem ser de todo maus ou de todo bons. Papa Júlio II $(1505)$

Objetivos: (a) Expulsar de Bolonha a casa dos Bentivogli; (b) Expulsar de Perúgia o tirano Giovampagolo Baglioni.

\section{Acontecimentos}

O papa Júlio II entrou na cidade desarmado, conseguiu a rendição de Giovampagolo, deixando em seu lugar um governador de sua confiança. Portanto, Giovampagolo apesar de

\footnotetext{
35 TITO LIVIO, II, 1-2. Cf. MAQUIAVEL, (2007, p. 87-88).

${ }^{36}$ MAQUAIVEL, (op. cit, p. 88-89).

${ }^{37}$ Ibidem, (2007, p. 89-90).
} 
incestuoso e parricida, acovardou-se frente ao papa, mostrando-se fraco e temente, ao não ousar contra o papa e sua comitiva, perdeu a oportunidade de glorificar-se como alguém audacioso e destemido em seu reino, sendo, portanto, submetido por sua própria fraqueza e covardia.

\section{REFERÊNCIAS BIBLIOGRÁFICAS}

\section{Obras primárias}

MAQUIAVEL, Nicolau. Discursos sobre a Primeira Década de Tito Lívio. Glossário e revisão técnica: Patrícia Fontoura Aranovich; Tradução MF; edição de texto: Karina Jannini. São Paulo: Martins Fontes, 2007.

Política e Gestão Florentina. Série Ciências Sociais na Administração. Tradutor Renato Ambrósio. Prefácio Kurt Mettenheim. Departamento de Fundamentos Sociais e Jurídicos da Administração. FGV-EAESP, 2010a.

Príncipe. Organização e tradução de José Antônio Martins. São Paulo: Hedra, 2010b.

. Legazioni, commissarie, scritti di governo. Tomo I. Legazione a Caterina Sforza (14981500). Roma: Salerno Editrice, 2002.

LIVIO, Tito. História de Roma. Introdução, Tradução e notas de Paulo Matos Peixoto, São Paulo: Editora Paumape S.A, 1989.

VIRGILIO (Publius Virgilius Maro). Eneida. (Edição bilíngue). Tradução de Carlos Alberto Nunes, organização, apresentação e notas de João Angelo de Oliva Neto - São Paulo: Editora 34, 2014.

\section{Obras secundárias}

ALBERTZ, Rainer. Historia de la religión de Israel en tiempos del Antiguo Testamento. Madrid: Editorial Trotta, 1999.

AMES, José Luiz. Maquiavel a lógica da ação política. Cascavel: Edunioeste, 2002.

Lei ou violência: a legitimação política em Maquiavel. In: Trans/Form/Ação, Marília, v.34, n.1, p.21-42, 2011.

BENEVENUTO, Flávia Roberta de Souza. 'Virtù' e valores no pensamento de Maquiavel. Dissertação de Mestrado. - Departamento de Filosofia da UFMG, Belo Horizonte, 2003.

BIGNOTTO, Newton. Maquiavel Republicano. São Paulo: Edições Loyola, 1991.

BOBBIO, Norberto. O terceiro ausente. Ensaios e discursos sobre a paz e a guerra. São Paulo, Editora Manole, 2009.

BRIGHT, John. História de Israel. 7. ed. rev. e ampl. São Paulo: Paulus, 2003.

CAPATA, A. Machiavelli: Tute le opere stoiche politiche e letterarie. Florença, I Mamnut, 1998.

CASSIRER, Ernst. El Mito del Estado. México: Fondo de Cultura Económica, 1992. 
CAZELLES. Henri. História Politica de Israel: desde das origens até Alexandre Magno. São Paulo: Paulus, 1987.

DI SALVO, Angelo J. "Spanish Guides to Princes and the Political Theories in Don Quijote". In: Cervantes: Bulletin of the Cervantes Society of America 9.2 (1989): 43-60. Disponível em: Acesso em: 29.9.2020.

DONNER, Herbert. História de Israel e dos povos vizinhos. São Leopoldo, RS: Sinodal; Petrópolis, RJ: Vozes, 1997.

ESCOREL, Lauro. O Pensamento político de Maquiavel. In: Humanidades. Brasília, n. 8, p. 18-52, jul./set. 1984.

GUNNEWEG, A. H. J. História de Israel: dos primórdios até Bar Kochba e de Theodor Herzl até os nossos dias. São Paulo: Teológica-Loyola, 2005.

HAHN, Fábio André. "Espelhos de Príncipes: considerações sobre o gênero". In: História eHistória, 4.11.2008. Disponível em: Acesso em 29.9.2020.

HAHN, F. A. "A guerra na obra de Maquiavel". In: Revista Varia scientia, n. 01, p. 135-138, 2001.

LEFORT, Claude. Le travail de l'ouevre: Machiavel. Paris: Gallimard, 1972.

MARCHAND, J. J. Niccolò Machiavelli - I Primi Scritti Politici. Editora Antenore, Padova, 1975.

MÉNISSIER, Thierry. Vocabulário de Maquiavel. Tradução de Cláudia Berliner, Rev. Técnica de Patrícia Fontoura Aranovich, São Paulo, 2012.

NEGRI, Antônio. O Poder Constituinte - ensaio sobre as alternativas da modernidade. Rio de Janeiro: DP\&A, 2002

PANCERA, Carlos G. K. "Ragionare dello stato: A representação do estado no vocabulário macheveliano dos Primeiros Escritos Políticos". In: O que nos faz pensar, n²7, maio de 2010.

PITKIN, Hannah. Gênero e política no pensamento de Maquiavel. In: Revista Brasileira de Ciência Política, nº12. Brasília, setembro - dezembro de 2013.

PRICE, R. The Senses of virtù Machiavelli. In: European Studies Review, 1973, 3, (pp. 315-3).

SANTOS, Laerte Moreira. A virtú do povo na Filosofia de Maquiavel. - Dissertação de Mestrado da USP (Universidade de São Paulo), São Paulo, 2011.

SANTOS, Rodrigo. Força, Armas, Leis e Milícia em I Primi Scritti Politici, de Maquiavel. Dissertação de Mestrado. Pontifícia Universidade Católica de São Paulo. São Paulo, 2015.

SENELLART, Michel. As artes de governar: do regime medieval ao conceito de governo. Trad. Paulo Neves. São Paulo: Ed. 34, 2006.

SOARES, Nair de Nazaré Castro. O príncipe ideal no século XVI e a obra de D. Jerónimo Osório. Coimbra: Instituto Nacional de Investiga, 1994. 